\title{
Same-Sex Domestic Partnerships and Lower-Risk Behaviors for STDs, Including HIV Infection
}

\author{
Jeffrey D. Klausner, MD, MPH \\ San Francisco Department of Public Health \\ Lance M. Pollack, PhD \\ University of California \\ Will Wong, MD \\ San Francisco Department of Public Health \\ Mitchell H. Katz, MD \\ San Francisco Department of Public Health
}

\begin{abstract}
To determine the association between domestic partnership status and risk behaviors for sexually transmitted diseases, including HIV infection, we analyzed data from a population-based intervieweradministered telephone survey of 2,881 gay men in San Francisco, Los Angeles, New York and Chicago conducted in November 1996 to February 1998. Men in domestic partnerships had a statistically significantly lower prevalence of multiple partnerships, "one-night stands," and unprotected anal intercourse with a non-primary partner than either men
\end{abstract}

Jeffrey D. Klausner is Director of STD Prevention and Control Services for the San Francisco Department of Public Health, CA. Lance M. Pollack is affiliated with Center for AIDS Prevention Studies, University of California, San Francisco. Will Wong and Mitchell H. Katz are affiliated with San Francisco Department of Public Health, CA. Correspondence may be addressed: Jeffrey D. Klausner, STD Prevention and Control Services, 1360 Mission Street, Suite \#401, San Francisco, CA, 94103.

Journal of Homosexuality, Vol. 51(4) 2006

Available online at http://jh.haworthpress.com (C) 2006 by The Haworth Press, Inc. All rights reserved. doi:10.1300/J082v51n04_07 
with steady partners not identified as domestic partners or men without a steady partner. These findings were independent of age. Men in domestic partnerships had decreased risk behaviors for sexually transmitted diseases, including HIV infection, suggesting but not proving, that conferring legal status to same-sex unions might decrease sexual risk behavior. doi:10.1300/J082v51n04_07 [Article copies available for a fee from The Haworth Document Delivery Service: 1-800-HAWORTH. E-mail address: $<$ docdelivery@haworthpress.com> Website: <http://www.HaworthPress.com> (C) 2006 by The Haworth Press, Inc. All rights reserved.]

KEYWORDS. Domestic partnership, men who have sex with men, HIV infection, risk behavior, AIDS policy

\section{INTRODUCTION}

Recent increases in sexually transmitted diseases (STDs) including HIV infection in men who have sex with men (MSM) have been reported in several American and western European cities (Chen et al., 2002; CDC 2002; Doherty et al., 2002; and Stolte et al., 2001). These increases have occurred despite well-established HIV prevention campaigns targeted to MSM in these communities. New approaches for prevention are clearly needed.

Legalization of marriage for same-sex couples has been advocated on the basis of equal rights for all persons regardless of the sex of a chosen life partner. However, it is also possible that the social and legal recognition afforded by civil unions serves to encourage monogamy and thereby decrease the risk behaviors for STDs and HIV infection. We examined whether MSM who reported being in a domestic partnership had fewer risk behaviors for STDs and HIV infection than those not in domestic partnerships.

\section{METHODS}

The Urban Men's Health Study was a representative sample of adult MSM living in the selected zip codes containing a majority of MSM households in Chicago, Los Angeles, New York and San Francisco (Catania et al., 2001). To obtain the sampling frame researchers mapped MSM AIDS caseload data, male-male partnered household data from the 1990 Census, addresses of gay-oriented businesses and services, 
and areas designated as gay neighborhoods by local informants to identify residential concentrations of MSM (Binson et al., 1996). Zip codes with estimated cost per interview above $\$ 1,000$ were dropped from the sampling frame. A random-digit-dial sample was drawn from the telephone exchanges serving those selected zip codes. Men age 18 or older who self-identified as gay/bisexual and/or reported having same gender sex since age 14 qualified for inclusion in the study. Between November 1996 and February 1998, a total of 2,881 (78\%) of 3,700 men in eligible households completed interviews. Interviews covered a range of social, psychological and health-related topics with an emphasis on HIV-related issues.

Questions on primary or nonprimary partner status were asked just before the section on sexual behavior. Participants were asked if they had a primary partner (i.e., primary partner or a man with whom the respondent had sex in the past 12 months and is "currently in love with or feel a special commitment to"). Domestic partnership status was asked at the end of the interview after all questions on sexual behavior. Participants were asked, "Do you have a relationship with a man who you would describe as your domestic partner or spouse?"

Participants without a domestic partner (or spouse) or primary partner were classified as having no steady partner. Thus, all participants were classified into three categories: (1) having a domestic partner or spouse (herein referred as "domestic partner"), (2) having a primary partner not identified as a domestic partner or (3) spouse or having no steady partner.

Since age was a potential confounder of the association between partnership status and risk behavior, we tested for an age by partnership status interaction. All data and significance values were weighted to reflect probability of selection, nonresponse and noncoverage, while maintaining proportionality between cities based on the estimated size of each city's MSM population. In order to obtain the correct p-values, the Chi-square statistic was converted to an F statistic with non-integer degrees of freedom using a second-order Rao and Scott correction (Stata Press, 2001). Analyses were performed using the STATA (Special Edition Version 7) SVYTAB procedure (College Station, TX).

\section{RESULTS}

Data for domestic partnership status were available for 2,694 (94\%) of 2881 men, of whom $1389(51.6 \%)$ reported no steady male partner, 
another $955(35.4 \%)$ reported having a male domestic partner and the remaining $350(13 \%)$ reported having a male primary partner who was not a domestic partner. Of the 955 respondents in domestic partnerships, 894 reported HIV status for both themselves and their domestic partner. Of those 894 domestic partnerships, 603 (67\%) were in a seroconcordant relationship, $156(17 \%)$ were in a sero-discordant relationship and 135 (15\%) were unknown.

There were no significant differences in HIV prevalence or in two co-factors of lifetime HIV risk like STD history and intravenous drug use among MSM reporting a domestic partner, a primary partner, or no steady partner (Table 1). However, there were differences with regard

TABLE 1. HIV Serostatus and HIV-Related Risk Factors by Type of Partner, Urban Men's Health Study, 1996-1998

\begin{tabular}{|c|c|c|c|c|c|}
\hline \multirow[t]{2}{*}{ Variable } & \multicolumn{4}{|c|}{ Type of Partner } & \multirow[b]{2}{*}{ P-value } \\
\hline & $\begin{array}{c}\text { Total } \\
(\mathrm{N}=2,694)\end{array}$ & $\begin{array}{l}\text { Domestic } \\
\text { Partner } \\
(\mathrm{N}=955)\end{array}$ & $\begin{array}{l}\text { Primary } \\
\text { Partner } \\
(\mathrm{N}=350)\end{array}$ & $\begin{array}{l}\text { No Steady } \\
\text { Partner } \\
(\mathrm{N}=1389)\end{array}$ & \\
\hline \multicolumn{6}{|l|}{ Lifetime } \\
\hline HIV-positive (\%) & 16.6 & 17.2 & 14.8 & 16.6 & .71 \\
\hline Ever told have an STD (\%) & 53.5 & 55.1 & 48.6 & 53.6 & .25 \\
\hline $\begin{array}{l}\text { Ever injected recreational } \\
\text { drugs }(\%)\end{array}$ & 8.0 & 7.3 & 9.3 & 8.2 & .60 \\
\hline \multicolumn{6}{|l|}{ Past year } \\
\hline $\begin{array}{l}\text { Two or more male sex } \\
\text { partners (\%) }\end{array}$ & 61.2 & 42.6 & 81.1 & 69.0 & $<.01^{2,3,4}$ \\
\hline "One-night stand" (\%) & 52.2 & 35.6 & 62.5 & 61.0 & $<.01^{2,3}$ \\
\hline $\begin{array}{l}\text { Unprotected anal intercourse } \\
\text { with a male non-primary } \\
\text { partner }(\%)\end{array}$ & 21.8 & 12.4 & 24.2 & 27.6 & $<.01^{2,3}$ \\
\hline $\begin{array}{l}\text { Unprotected anal intercourse } \\
\text { with a sero-discordant male } \\
\text { partner in past year }{ }^{1}(\%)\end{array}$ & 4.9 & 4.9 & 6.3 & 4.5 & .94 \\
\hline \multicolumn{6}{|c|}{$\begin{array}{l}{ }^{1} \text { Defined as either an HIV-positive respondent who has unprotected insertive anal intercourse with an } \\
\text { HIV-negative/indeterminate male partner, or an HIV-negative/untested respondent who has unprotected } \\
\text { receptive anal intercourse with an HIV-positive/HIV-indeterminate male partner. This determination is } \\
\text { based on respondents' reports concerning their four most recent sexual partners within the past year. } \\
{ }^{2} \text { Domestic partner versus primary partner post hoc comparison significant at } p<.0167 \text {. } \\
{ }^{3} \text { Domestic partner versus no special partner post hoc comparison significant at } p<.0167 \text {. } \\
{ }^{4} \text { Primary partner versus no special partner post hoc comparison significant at } p<.0167 \text {. }\end{array}$} \\
\hline
\end{tabular}


to risk behaviors for STDs or HIV infection in the prior year. Men with domestic partners were significantly less likely to have had two or more male sex partners, to have had a "one-night stand," or to have had unprotected anal intercourse with a male nonprimary partner than men with nondomestic primary partnerships or those with no steady partner. There were no differences in the rate of unprotected anal intercourse with a sero-discordant male partner in the past year, but the reported rates were low for all three groups.

Since age, partnership status and risk behavior would likely be related, we tested for an age by partnership status interaction using logistic regression analysis. The peak prevalence for domestic partnerships was between 30-39 years (41\%) and 40-49 years (37\%) compared with 18 -29 years $(30 \%)$ and $>49$ years $(28 \%)$. Table 2 shows the prevalence by age group and partnership status of the two risk behaviors for which significant interactions $(\mathrm{p}<.05)$ were found: two or more male sex partners and "one-night stands" in the past year. In general, prevalence of those risk behaviors declined with age, but the decline was particularly precipitous in the oldest age group of men with no steady partner. Regardless, in every age group respondents with a domestic partner had the lowest prevalence of risk behavior.

Table 3 shows the prevalence of unprotected anal intercourse (UAI) in the past year with a male partner and with a male nonprimary partner by serostatus of the domestic partnership. The data indicate that knowl-

TABLE 2. Prevalence of Multiple Partnerships and "One-Night Stands" in the Past Year by Age Group and Partnership Status, Urban Men's Health Study, 1996-1998

\begin{tabular}{lcccc}
\hline & \multicolumn{4}{c}{ Age Group (years) } \\
\cline { 2 - 5 } & $\begin{array}{c}18-29 \\
(\mathrm{n}=534)\end{array}$ & $\begin{array}{c}30-39 \\
(\mathrm{n}=1036)\end{array}$ & $\begin{array}{c}40-49 \\
(\mathrm{n}=683)\end{array}$ & $\begin{array}{c}50+ \\
(\mathrm{n}=440)\end{array}$ \\
\hline Two or more male sex partners & & & & \\
Past year & 53.2 & 41.7 & 39.6 & 38.4 \\
$\quad$ Domestic partner (\%) & 82.9 & 86.2 & 76.4 & 62.5 \\
Primary partner (\%) & 76.1 & 79.6 & 68.0 & 45.6 \\
$\quad$ No steady partner (\%) & & & & \\
"One-night stands" & 45.9 & 36.9 & 32.2 & 24.8 \\
Domestic partner (\%) & 64.8 & 64.5 & 59.7 & 53.1 \\
Primary partner (\%) & 71.4 & 70.9 & 60.2 & 35.7 \\
$\quad$ No steady partner (\%) & & & & \\
\hline
\end{tabular}


TABLE 3. Prevalence of UAI in the Past Year with Domestic Male Partner and a Male Non-Domestic Partner by Serostatus of Domestic Partnership, Urban Men's Health Study, 1996-1998

\begin{tabular}{lcccc}
\hline & \multicolumn{3}{c}{ Serostatus of Partnership } & \\
\cline { 2 - 4 } & $\begin{array}{c}\text { Concordant } \\
(\mathrm{n}=603)\end{array}$ & $\begin{array}{c}\text { Discordant } \\
(\mathrm{n}=156)\end{array}$ & $\begin{array}{c}\text { Unknown } \\
(\mathrm{n}=135)\end{array}$ & P-value \\
\hline UAI with a male domestic partner (\%) & 56.5 & 24.2 & 51.5 & $<.001^{1,2}$ \\
UAI with a male non-domestic partner (\%) & 11.7 & 15.2 & 17.2 & .657 \\
\hline
\end{tabular}

${ }^{1}$ Discordant versus concordant post hoc comparison significant at $\mathrm{p}<.0167$.

${ }^{2}$ Discordant versus unknown post hoc comparison significant at $p<.0167$.

edge of partner serostatus affected sexual risk behavior within domestic partnerships.

\section{DISCUSSION}

Although same-sex civil unions have been gaining political, social and legal momentum in the past few years in the United States and Western Europe, these are the first data to indicate that same-sex male civil unions are associated with lower-risk behavior for HIV infection and other STDs (Pear 2002 and Hoge 2002). Moreover, the effect is specific to having a domestic partner, not just a primary partner, suggesting that societal and legal recognition have an impact on the maintenance of safer sex behaviors.

As is true of all observational studies, our data cannot prove that there was a causal relationship between civil unions and decreased risk behaviors. Although the association between domestic partnership and decreased risk behavior was unaffected by adjustment for age, there remains the possibility that our results are confounded by some other factor. It is possible that couples that participate in domestic partnerships have decreased risk behaviors and would have these lower-risk profiles whether or not it was possible for them to participate in a civil union. Nonetheless, societal support for civil unions, such as domestic partner insurance, pension, and death benefits might strengthen existing civil unions and encourage others to form such unions.

A major strength of our data is that the samples are representative of MSM living in these four urban areas in the United States. Our data may 
not generalize, however, to MSM living in other American cities or outside of urban areas. In addition, a modest proportion of study respondents in domestic partnerships were with HIV sero-discordant partners or were unaware of the infection status of their partner, so the true risk for HIV infection in those domestic partnerships is unknown. That said, domestic partners in sero-discordant relationships were less likely to practice risk sexual behavior than those in sero-concordant relationships. Further research should be done on how domestic partnerships may decrease risk behaviors, and what proportion of the population would consider entering into domestic partnerships if these partnerships conferred the same rights as opposite-sex marriage.

Marriage has challenges, but also obvious financial and social benefits for those who can access it legally. We have shown that civil unions may also confer a benefit to those at particular risk for STDs and HIV infection in the United States through an associated reduction in sexual risk behavior. Our findings should add strength to the same-sex marriage movement in the United States and abroad.

\section{REFERENCES}

Binson, D., Moscowitz, J., Mills, T., Anderson, K., Paul, J., Stall, R., Catania, J. (1996). Sampling men who have sex with men: strategies for a telephone survey in urban areas in the United States. American Statistical Association 1996 Proceedings of the Section on Survey Research Methods Volume I; 1996 August 4-8; Chicago, IL. Alexandria, VA: American Statistical Association.

Catania J.A., Osmond, D., Stall, R.D., Pollack, L., Paul, J.P., Blower, S., Binson, D., Canchola, J.A., Mills, T.C., Fisher, L., Choi, K.H., Porco T., Turner, C., Blair J., Henne, J., Bye L,L., Coates, T.J. (2001). The continuing HIV epidemic among men who have sex with men. American Journal of Public Health, 91(6), 907-14.

Centers For Disease Control And Prevention. Primary and secondary syphilis among men who have sex with men-New York City, 2001. (2002). JAMA, 288(15), 1840-2.

Chen, S.Y., Gibson, S., Katz, M.H., Klausner, J.D., Dilley, J.W., Schwarcz, S.K., Kellogg, T.A., Mcfarland, W. (2002). Continuing increases in sexual risk behavior and sexually transmitted diseases among men who have sex with men: San Francisco, Calif., 1999-2001, USA. American Journal of Public Health, 92(9), 1387-8.

Doherty, L., Fenton, K.A., Jones, J., Paine T.C., Higgins, S.P., Williams, D. And Palfreeman, A. Syphilis: old problem, new strategy. (2002) British Medical Journal, 325(7356), 153-156.

Hoge W. Britain announces proposal for same-sex partnerships. The New York Times. December 7, 2002: A8. 
Pear, R. Legal group urges states to update their family law. The New York Times. November 30, 2002: A1.

Stata Reference Manual, Release 7, Volume 4 Su-Z, College Station, TX: Stata Press; 2001: 78-94.

Stolte, I.G., Dukers, N.H., De Wit, J.B., Fennema, J.S., Coutinho R.A. Increase in sexually transmitted infections among homosexual men in Amsterdam in relation to HAART. (2001). Sexually Transmitted Infections, 77(3), 184-6.

$$
\text { doi:10.1300/J082v51n04_07 }
$$

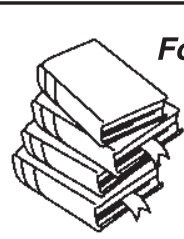

For FACULTYIPROFESSIONALS with journal subscription recommendation authority for their institutional library ... . If you have read a reprint or photocopy of this article, would you like to make sure that your library also subscribes to this journal? If you have the authority to recommend subscriptions to your library, we will send you a free complete (print edition) sample copy for review with your librarian.

1. Fill out the form below and make sure that you type or write out clearly both the name of the journal and your own name and address. Or send your request via e-mail to docdelivery@ haworthpress.com including in the subject line "Sample Copy Request" and the title of this journal.

2. Make sure to include your name and complete postal mailing address as well as your institutional/agency library name in the text of your e-mail.

[Please note: we cannot mail specific journal samples, such as the issue in which a specific article appears. Sample issues are provided with the hope that you might review a possible subscription/e-subscription with your institution's librarian. There is no charge for an institution/campus-wide electronic subscription concurrent with the archival print edition subscription.]

$\square$ YES! Please send me a complimentary sample of this journal:

(please write complete journal title here-do not leave blank)

I will show this journal to our institutional or agency library for a possible subscription. Institution/Agency Library:

Name:

Institution:

Address:

City: State: Zip: 